\title{
Isolated calf deep venous thrombosis: frequency on venous ultrasound and clinical characteristics
}

\author{
Thomas Heller ${ }^{1 *} \mathbb{D}$, Mattes Becher ${ }^{1}$, Jens-Christian Kröger ${ }^{1}$, Ebba Beller ${ }^{1}$, Susanne Heller ${ }^{1}$, Raimund Höft ${ }^{2}$, \\ Marc-André Weber ${ }^{1}$ and Felix G. Meinel ${ }^{1}$
}

\begin{abstract}
Background: It remains controversial whether to include calf veins in the initial ultrasound evaluation of suspected deep venous thrombosis (DVT). We sought to investigate the frequency and clinical characteristics of isolated calf DVT.

Materials and methods: In this retrospective analysis, we investigated a cohort of 596 patients (median age 69 years, 52.3\% women) who had been imaged with complete lower extremity venous duplex ultrasound for suspected acute DVT. Radiology reports were analyzed for the presence and localization of DVT. Clinical information was collected from patients' electronic charts.

Results: DVT was found in 157 patients (26.3\%), of which 74 patients (47.1\%) had isolated calf DVT. Isolated calf DVTs were located in the posterior tibial veins (22 patients, 29.7\%), peroneal veins (41 patients, 55.4\%) and muscle veins (19 patients, 25.7\%). There were no differences in age or sex between patients with isolated calf DVT and patients with proximal DVT. Isolated calf DVT was more commonly associated with leg pain $(52.7 \%$ vs. $33.7 \%, p=$ $0.0234)$ and less commonly associated with subjective leg swelling ( $35.1 \%$ vs. $55.4 \%, p=0.0158)$ and objectively measured difference in leg circumference (23\% vs. 39.8\%, $p=0.0268)$. D-Dimers were significantly lower in patients with isolated lower leg DVT (median 2.3 vs. $6.8 \mathrm{mg} / \mathrm{L}, p<0.0001$ ) compared to patients with proximal DVT.
\end{abstract}

Conclusions: Isolated calf DVT represents approximately half of DVT cases and has different clinical characteristics than proximal DVT.

Keywords: Deep venous thrombosis, Duplex ultrasound, Compression ultrasound

\section{Background}

Venous ultrasound is the standard imaging test for patients with suspected deep venous thrombosis (DVT). There is, however, great variability in the ultrasound technique performed for suspected DVT between institutions $[1,2]$ and guidelines [3-8]. In particular, there is

\footnotetext{
* Correspondence: thomas.heller@uni-rostock.de

'Institute of Diagnostic and Interventional Radiology, Pediatric Radiology and Neuroradiology, University Medical Centre Rostock, Ernst-Heydemann-Str. 6, 18057 Rostock, Germany

Full list of author information is available at the end of the article
}

disagreement on whether to include the calf veins in the initial ultrasound evaluation of suspected DVT. Some institutions perform ultrasound examinations with a limited range from the groin to the knee - sometimes in the form of two-point or three-point compression ultrasound as the initial test [8-15]. If negative, this is typically followed by a second ultrasound examination within one week to safely exclude DVT $[8,16]$.

The clinical importance of isolated calf-vein DVT is incompletely understood with regards to the risks for propagation into the popliteal and femoral vein,

(c) The Author(s). 2021 Open Access This article is licensed under a Creative Commons Attribution 4.0 International License, which permits use, sharing, adaptation, distribution and reproduction in any medium or format, as long as you give appropriate credit to the original author(s) and the source, provide a link to the Creative Commons licence, and indicate if changes were made. The images or other third party material in this article are included in the article's Creative Commons licence, unless indicated otherwise in a credit line to the material. If material is not included in the article's Creative Commons licence and your intended use is not permitted by statutory regulation or exceeds the permitted use, you will need to obtain permission directly from the copyright holder. To view a copy of this licence, visit http://creativecommons.org/licenses/by/4.0/ The Creative Commons Public Domain Dedication waiver (http://creativecommons.org/publicdomain/zero/1.0/) applies to the data made available in this article, unless otherwise stated in a credit line to the data. 
pulmonary embolism and the development of a postthrombotic syndrome. A certain percentage of isolated asymptomatic distal DVTs will extend to the proximal veins if untreated. This rate was previously thought to be on the order of $15-20 \%[17,18]$ but was significantly lower (5\%) in the placebo arm of the prospective randomized CACTUS trial [19]. Nevertheless, the benefit of treating patients with isolated calf DVT remains uncertain and controversial [8, 18-25].

In light of this ongoing controversy, we sought to investigate the frequency and clinical characteristics of isolated calf DVT on complete duplex ultrasound examination as the initial test in patients with suspected DVT.

\section{Material and methods}

\section{Study design, ethical approval, and patient selection}

This study was granted approval by our institutional review board (Ethics Committee, Faculty of Medicine, University of Rostock, Germany). The institutional review board granted permission to access and use the medical records and waived the need for informed consent for this retrospective analysis, in which the collected data was fully anonymized prior to analysis. This was a single-center cohort study. We retrospectively included all patients who were examined with venous ultrasound of the legs at our institution in the year 2014 for suspected acute DVT. During this year, venous ultrasound was predominantly performed by subspecialized radiologists with $>25$ years of experience in vascular sonography (TH and JCK). We identified eligible patients through a retrospective search of our radiology information system. We excluded patients in whom venous ultrasound had been performed with an indication other than suspected acute DVT. Follow-up ultrasound examinations in patients with an established diagnosis of DVT in the past 3 months were also excluded from this analysis. (Fig. 1). We further excluded patients referred for duplex ultrasound because of a recent diagnosis of acute pulmonary embolism under the assumption that isolated calf DVT in patients with pulmonary embolism may not be truly isolated calf DVT but rather the remnant of a more extensive proximal DVT, much of which has embolized. We did not exclude patients with a past $(>3$ months) history of DVT.

\section{Ultrasound technique}

All ultrasound examinations were performed on a Toshiba Aplio XG SSA 770A ultrasound machine. Based on previous studies demonstrating D-Dimer testing and Wells score are of limited accuracy in isolated calf DVT [26], our practice is to perform venous ultrasound in all patients with clinically suspected DVT irrespective of Ddimer levels and Wells score. Our institutional standard in suspected DVT is to always perform a complete duplex ultrasound of the symptomatic leg(s). Our institution's technique for whole leg venous ultrasound has been previously described in detail [27].

\section{Analysis of radiology reports}

Radiology reports were retrospectively reviewed by a medical student (initials blinded) for the presence and location of DVT. If the localization could not be precisely determined from the radiology report, the images of the ultrasound examination stored in our PACS were viewed by a board-certified radiologist to determine localization. Patients were classified as having proximal DVT if any portion of the DVT was in the popliteal vein, femoral and/or iliac veins. In contrast, patients were classified as having isolated calf DVT, if DVT was exclusively in one or more veins below the knee (posterior tibial veins, peroneal veins or muscle veins of the calf). Patients with bilateral DVT were classified according to the leg with the more proximally located DVT.

\section{Analysis of clinical data}

Clinical information including age, sex, signs and symptoms, risk factors, Wells scores and D-Dimer levels were collected from patients' electronic charts.

\section{Statistical analysis}

Commercially available software (GraphPad Prism, version 8.4.2, GraphPad Software Inc) was used for statistical analysis. For continuous variables, 25th, 50th (median) and 75th percentile were calculated. The Mann-Whitney test was used for comparison of continuous variables. For categorical variables, frequencies and proportions were calculated. Fisher's exact test was used to compare the distribution of categorical variables between groups. An alpha level of $<.05$ was considered to indicated statistically significant differences.

\section{Results}

\section{Patient characteristics}

Our final study cohort consisted of 596 patients, of which 312 (52.3\%) were women. Patient characteristics are summarized in Table 1 . Median age was 69 years. The most common local symptoms across all 596 patients were leg pain (40.9\%) and leg swelling (40.6\%). $12.9 \%$ of patients had active malignancy and $16.4 \%$ of patients had a past medical history of DVT (Table 1).

\section{Comparison of patients with DVT vs. patients without DVT on ultrasound}

DVT was found in 157 of 596 patients (26.3\%, Table 1 and Fig. 1). DVT was right-sided in 71 of 157 patients (45.2\%), and left-sided in 71 of 157 patients (45.2\%), resulting in a right/left ratio of 1.0. 15 patients had 


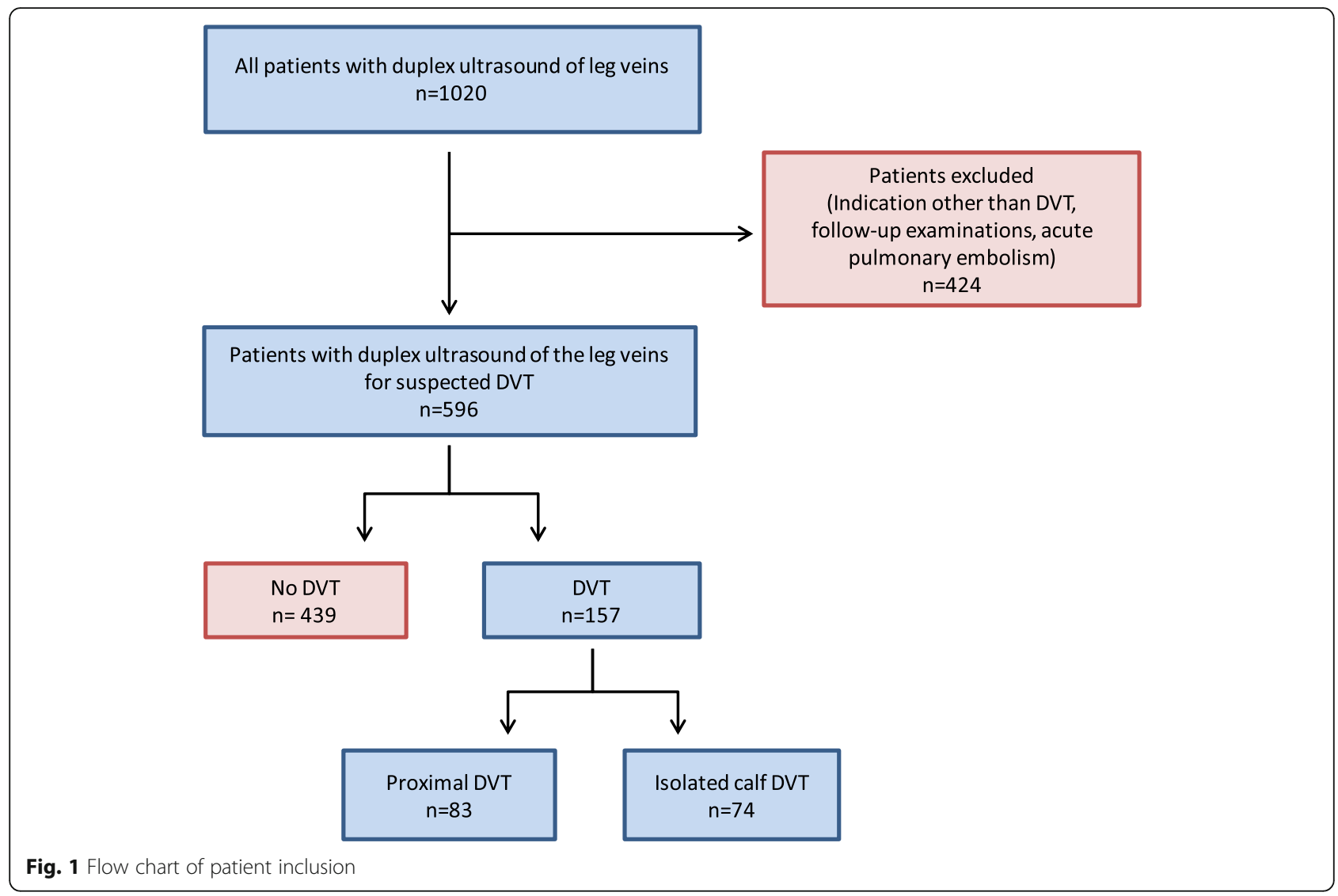

bilateral DVT (9.6\% of all patients with DVT). Patients with DVT were significantly more likely to have a prior history of DVT $(29.3 \%$ vs. $11.8 \%, p=0.0004)$ than patients without DVT on ultrasound. Patients with DVT had higher Wells scores (median 2 vs. $1, p<0.0001$ ) and higher D-Dimer levels (median 4.2 vs. $1.4 \mathrm{mg} / \mathrm{L}, p<$ $0.0001)$ than patients without DVT. There were no differences in age, sex or leg symptoms between patients with and without DVT on ultrasound.

\section{Frequency of isolated lower leg DVT}

Among the 157 patients with DVT, 74 patients (47.1\%) had isolated lower leg DVT. Isolated calf DVT was right-sided in 34 of 74 patients (45.9\%), and left-sided in 38 of 74 patients (51.4\%), resulting in a right/left ratio of 0.9 . Calf DVT was bilateral in 2 cases $(2.7 \%)$. Isolated lower leg DVTs were located in the posterior tibial veins in 22 patients $(29.7 \%)$, peroneal veins in 41 patients (55.4\%) and muscle veins (gastrocnemius or soleus) in 19 patients (25.7\%). Eight of these patients had DVT in multiple calf veins.

\section{Comparison of patients with isolated lower leg DVT vs. patients with proximal DVT}

There were no differences in age, sex or risk factors between patients with isolated lower leg DVT and patients with a proximal DVT (Table 2). Isolated lower leg DVT was more commonly associated with leg pain $(52.7 \%$ vs. $33.7 \%, p=0.0234$ ) and less commonly associated with subjective leg swelling ( $35.1 \%$ vs. $55.4 \%, p=0.0158)$ and objectively measured difference in leg circumference ( $23 \%$ vs. $39.8 \%, p=0.0268$ ). There was a trend for Wells score to be lower in patients with isolated lower leg DVT (median 2 vs. 3, $p=0.0915$ ). D-Dimers were significantly lower in patients with isolated lower leg DVT (median 2.3 vs. $6.8 \mathrm{mg} / \mathrm{L}, p<0.0001$ ) compared to patients with proximal DVT. Three of 74 patients $(4.1 \%)$ with isolated calf DVT had normal D-dimers $(<0.5 \mathrm{mg} /$ L) compared to 1 of 83 patients (1.2\%) with proximal DVT.

\section{Discussion}

Isolated calf vein DVT is frequent and represents 28 to $70 \%$ of all lower-limb DVTs diagnosed on ultrasound series [15, 28-33]. Our results are in line with these earlier reports since we found that in our series $47 \%$ of DVTs diagnosed on complete duplex ultrasound as the initial tests were isolated calf vein DVTs. This suggests that an initial ultrasound evaluation performed with a limited range (from the groin to the popliteal vein) will miss almost half of DVT cases. 
Table 1 Characteristics of Study Population

\begin{tabular}{|c|c|c|c|c|c|c|c|c|}
\hline & & \multicolumn{2}{|c|}{$\begin{array}{l}\text { All patients } \\
(n=596)\end{array}$} & \multicolumn{2}{|c|}{$\begin{array}{l}\text { No DVT } \\
(n=439)\end{array}$} & \multicolumn{2}{|c|}{$\begin{array}{l}\text { DVT } \\
(n=157)\end{array}$} & \multirow[t]{2}{*}{$P$-Value } \\
\hline & & $\mathbf{N}$ & $\%$ & $\mathbf{n}$ & $\%$ & $\mathbf{N}$ & $\%$ & \\
\hline \multicolumn{2}{|l|}{ Females } & 312 & $52.3 \%$ & 223 & $50.8 \%$ & 89 & $56.7 \%$ & 0.2264 \\
\hline \multicolumn{2}{|l|}{ Age in years, median (interquartile range) } & \multicolumn{2}{|c|}{$69(55-78)$} & \multicolumn{2}{|c|}{$69(55-77)$} & \multicolumn{2}{|c|}{$70(55-79)$} & 0.2393 \\
\hline \multirow[t]{4}{*}{ Presentation } & Leg pain & 244 & $40.9 \%$ & 177 & $40.3 \%$ & 67 & $42.7 \%$ & 0.6368 \\
\hline & Leg swelling & 242 & $40.6 \%$ & 170 & $38.7 \%$ & 72 & $45.9 \%$ & 0.1300 \\
\hline & Circumference difference & 161 & $27 \%$ & 111 & $25.3 \%$ & 50 & $31.8 \%$ & 0.1172 \\
\hline & Redness & 40 & $6.7 \%$ & 30 & $6.8 \%$ & 10 & $6.4 \%$ & 0.9999 \\
\hline \multirow[t]{4}{*}{ Risk factors } & Known coagulopathy & 9 & $1.5 \%$ & 6 & $1.4 \%$ & 3 & $1.9 \%$ & 0.7043 \\
\hline & Active cancer & 77 & $12.9 \%$ & 53 & $12.1 \%$ & 24 & $15.3 \%$ & 0.3320 \\
\hline & Previous DVT & 98 & $16.4 \%$ & 52 & $11.8 \%$ & 46 & $29.3 \%$ & 0.0004 \\
\hline & Wells score, median (interquartile range) & \multicolumn{2}{|c|}{$\begin{array}{l}1(0-2) \\
{[n=188]}\end{array}$} & \multicolumn{2}{|c|}{$\begin{array}{l}1(0-2) \\
{[n=135]}\end{array}$} & \multicolumn{2}{|c|}{$\begin{array}{l}2(1-4) \\
{[n=53]}\end{array}$} & $<0.0001$ \\
\hline Lab & $\begin{array}{l}\text { D-dimers in mg/L, } \\
\text { median } \\
\text { (interquartile range) }\end{array}$ & \multicolumn{2}{|c|}{$\begin{array}{l}1.7(0.8-4.1) \\
{[n=347]}\end{array}$} & \multicolumn{2}{|c|}{$\begin{array}{l}1.4(0.6-2.8) \\
{[n=252]}\end{array}$} & \multicolumn{2}{|c|}{$\begin{array}{l}4.2 \\
(1.9-9.5) \\
{[n=95]}\end{array}$} & $<0.0001$ \\
\hline
\end{tabular}

$P$-values $<0.05$ appear bold

Our study goes beyond previously published data, as we analyzed the clinical characteristics of patients with isolated calf DVT compared to proximal DVT. Interestingly, we observed that isolated calf DVT was more commonly associated with leg pain than proximal DVT. It is generally thought that acute DVT triggers an inflammatory response [34] and that pain from DVT predominantly results from inflammation of the venous wall around the clot. A possible interpretation of our results would be that the local inflammatory response to DVT may be more pronounced in the smaller calf veins that in larger proximal veins.
Less surprisingly, we found that isolated calf DVT was less commonly associated with subjective leg swelling and objectively measured circumference difference. The most straightforward explanation for this finding is that in most patients, there is a single iliac, femoral and popliteal vein for each leg. DVT in these veins will thus occlude the entire deep venous outflow at this level. In contrast, there are multiple deep veins in the calf (typically paired peroneal veins, anterior and posterior tibial veins as well as muscle veins). Most cases of isolated calf DVT will occlude one or few of these veins and leave other deep calf veins patent.

Table 2 Characteristics of patients with isolated lower leg DVT vs. proximal DVT

\begin{tabular}{|c|c|c|c|c|c|c|c|c|}
\hline & & \multicolumn{2}{|c|}{$\begin{array}{l}\text { All patients } \\
\text { with DVT } \\
(n=157)\end{array}$} & \multicolumn{2}{|c|}{$\begin{array}{l}\text { Proximal DVT } \\
(n=83)\end{array}$} & \multicolumn{2}{|c|}{$\begin{array}{l}\text { Isolated lower } \\
\text { leg DVT } \\
(n=74) \\
\end{array}$} & \multirow[t]{2}{*}{$P$-Value } \\
\hline & & $\mathrm{N}$ & $\%$ & $\mathbf{n}$ & $\%$ & $\mathbf{n}$ & $\%$ & \\
\hline \multicolumn{2}{|l|}{ Females } & 89 & $56.7 \%$ & 45 & $54.2 \%$ & 44 & $59.5 \%$ & 0.5233 \\
\hline \multicolumn{2}{|l|}{ Age in years, median (interquartile range) } & \multicolumn{2}{|c|}{$70(55-79)$} & \multicolumn{2}{|c|}{$70(55-79.5)$} & \multicolumn{2}{|c|}{$69.5(55-78.75)$} & 0.7689 \\
\hline \multirow[t]{4}{*}{ Presentation } & Leg pain & 67 & $42.7 \%$ & 28 & $33.7 \%$ & 39 & $52.7 \%$ & 0.0234 \\
\hline & Leg swelling & 72 & $45.9 \%$ & 46 & $55.4 \%$ & 26 & $35.1 \%$ & 0.0158 \\
\hline & Circumference difference & 50 & $31.8 \%$ & 33 & $39.8 \%$ & 17 & $23 \%$ & 0.0268 \\
\hline & Redness & 10 & $6.4 \%$ & 7 & $8.4 \%$ & 3 & $4.1 \%$ & 0.3361 \\
\hline \multirow[t]{4}{*}{ Risk factors } & Known coagulopathy & 3 & $1.9 \%$ & 2 & $2.4 \%$ & 1 & $1.4 \%$ & 0.9999 \\
\hline & Active cancer & 24 & $15.3 \%$ & 15 & $18.1 \%$ & 9 & $12.2 \%$ & 0.3765 \\
\hline & Previous DVT & 46 & $29.3 \%$ & 25 & $30.1 \%$ & 21 & $28.4 \%$ & 0.8616 \\
\hline & Wells score, median (interquartile range) & \multicolumn{2}{|c|}{$\begin{array}{l}2(1-4) \\
{[n=53]}\end{array}$} & \multicolumn{2}{|c|}{$\begin{array}{l}3(1-4) \\
{[n=25]}\end{array}$} & \multicolumn{2}{|c|}{$\begin{array}{l}2(1-3) \\
{[n=28]}\end{array}$} & 0.0915 \\
\hline Lab & $\begin{array}{l}\text { D-Dimer in mg/L, } \\
\text { median (interquartile range) }\end{array}$ & \multicolumn{2}{|c|}{$\begin{array}{l}4.2(1.9-9.5) \\
{[n=95]}\end{array}$} & \multicolumn{2}{|c|}{$\begin{array}{l}6.8(4.2-12) \\
{[n=51]}\end{array}$} & \multicolumn{2}{|c|}{$\begin{array}{l}2.3(1.1-5.0) \\
{[n=44]}\end{array}$} & $<0.0001$ \\
\hline
\end{tabular}


Regarding laboratory values, we observed that levels of D-dimers were significantly lower in patients with isolated lower leg DVT compared to patients with proximal DVT. This likely reflects the greater thrombus burden in patients with DVT in larger, more proximal veins compared to isolated calf DVT. In our analysis, $4.1 \%$ of patients with isolated calf DVT had "negative" D-dimers (reference value of our hospital laboratory $<0,5 \mathrm{mg} / \mathrm{L}$ ) compared to 1 of 83 patients (1.2\%) with proximal DVT, suggesting that $\mathrm{D}$-dimer testing is somewhat less sensitive for isolated calf DVT.

Our results should be interpreted in light of the controversies about isolated calf DVT. It is known that venous ultrasonography is less accurate for isolated distal deep venous thrombosis than for proximal deep venous thrombosis [35]. Additionally, the clinical utility of including the calf veins in venous ultrasound is under debate because there is limited data about the natural course of isolated calf DVT and the benefit of anticoagulation [23, 24]. The only randomized, double-blind, placebo-controlled trial comparing lowmolecular-weight heparin to placebo for acute symptomatic calf DVT found that low-molecular-weight heparin was not superior to placebo in reducing the risk of proximal extension or venous thromboembolic events, but did increase the risk of bleeding [19]. On the other hand, a non-negligible long-term risk of recurrent venous thromboembolism was found when isolated calf DVT was treated with only a short-term (4-6 weeks) treatment of low-molecular weight heparin, in particular in patients with unprovoked isolated calf DVT or cancer [36].

According to the consensus guideline of the German, Swiss and Austrian Societies for Vascular Medicine [3] an additional advantage of whole-leg ultrasound is to identify differential diagnoses for example Baker's cyst, muscle fiber tear, aneurysm, hematoma, tumor as the reason for the patient's symptoms if negative for acute DVT. A recent study demonstrated that alternative diagnoses explaining leg symptoms can be detected on whole-leg ultrasound in two thirds of patients with no evidence of acute DVT [27].

Several limitations of our investigation should be mentioned. This single-center study had a limited cohort size and was performed at a university hospital. This may be a more selected cohort of patients than patients with suspected DVT seen by primary care physicians introducing possible selection bias. No external reference standard is available to confirm findings at ultrasound. Due to the retrospective nature of our investigation, Wells scores and D-Dimer levels were not available for all patients. Also, the precise time from symptom onset was not available in all cases. This may affect the findings on D-Dimer levels, which typically change over the course of acute DVT.

\section{Conclusion}

In summary, isolated calf DVT represents approximately half of DVT cases and has different clinical characteristics than proximal DVT. Venous ultrasound with a limited range from the groin to the knee will miss these cases.

\section{Abbreviations}

DVT: Deep venous thrombosis; PE: Pulmonary embolism

\section{Acknowledgements}

Not applicable.

\section{Authors' contributions}

$\mathrm{TH}$ and FGM designed the study. TH, MB, JCK, FGM collected and analysed the data. TH, MB, JCK, EB, SH, RH, MAW and FGM (all authors) participated in data interpretation. TH, MB and FGM drafted the manuscript. All authors made substantive revisions to the manuscript. All authors have approved the submitted and revised version of the manuscript. All authors have agreed both to be personally accountable for their own contributions and to ensure that questions related to the accuracy or integrity of any part of the work, even ones in which they were not personally involved, are appropriately investigated, resolved, and the resolution documented in the literature.

\section{Funding}

This research did not receive any specific funding. Open Access funding enabled and organized by Projekt DEAL.

\section{Availability of data and materials}

All materials described in the manuscript, including all relevant raw data, will be freely available from the corresponding author upon reasonable request by any scientist wishing to use them for non-commercial purposes.

\section{Declarations}

Ethics approval and consent to participate

This study was granted approval by our institutional review board (Ethics Committee, Faculty of Medicine, University of Rostock, Germany). The institutional review board granted permission to access and use the medical records and waived the need for informed consent for this retrospective analysis, in which the collected data was fully anonymized prior to analysis.

\section{Consent to publication}

Not applicable. This manuscript does not include details, images, or videos relating to an individual person.

\section{Competing interests}

The authors declare that there are no conflicts of interest related to this investigation.

\section{Author details}

${ }^{1}$ Institute of Diagnostic and Interventional Radiology, Pediatric Radiology and Neuroradiology, University Medical Centre Rostock, Ernst-Heydemann-Str. 6, 18057 Rostock, Germany. ${ }^{2}$ Department of Emergency Medicine, University Medical Centre Rostock, Rostock, Germany.

Received: 11 November 2020 Accepted: 12 October 2021

Published online: 30 October 2021

\section{References}

1. Needleman L, Cronan JJ, Lilly MP, Merli GJ, Adhikari S, Hertzberg BS, et al. Ultrasound for lower extremity deep venous thrombosis: multidisciplinary recommendations from the Society of Radiologists in ultrasound consensus conference. Circulation. 2018;137(14):1505-15. https://doi.org/10.1161/ CIRCULATIONAHA.117.030687. 
2. Pomero F, Dentali F, Borretta V, Bonzini M, Melchio R, Douketis JD, et al. Accuracy of emergency physician-performed ultrasonography in the diagnosis of deep-vein thrombosis: a systematic review and meta-analysis. Thromb Haemost. 2013;109(01):137-45. https://doi.org/10.1160/TH12-07-0473.

3. Deutsche Gesellschaft für Angiologie: Diagnostik und Therapie der Venenthrombose und der Lungenembolie, published online at https:// www.awmf.org/uploads/tx_szleitlinien/065-002I_S2k_VTE_2016-01.pdf.

4. International Union of Angiology. International Union of Angiology (2013) guideline for PREVENTION AND TREATMENT OF VENOUS THROMBOEMBOLISM. Int Angiol. 2013;32:111-258.

5. National Institute for Health and Care Excellence. The National Institute for Health and Care Excellence (NICE) guideline for Venous thromboembolism in adults: diagnosis and management 2013. https:/www.nice.org.uk/guidance/qs29.

6. Konstantinides SV, Meyer G. The 2019 ESC guidelines on the diagnosis and Management of Acute Pulmonary Embolism. Eur Heart J. 2019:40(42):34535. https://doi.org/10.1093/eurheartj/ehz726.

7. Lim W, Le Gal G, Bates SM, Righini M, Haramati LB, Lang E, et al. American Society of Hematology 2018 guidelines for management of venous thromboembolism: diagnosis of venous thromboembolism. Blood Adv. 2018;2(22):3226-56. https://doi.org/10.1182/bloodadvances.2018024828.

8. Kakkos SK, Gohel M, Baekgaard N, Bauersachs R, Bellmunt-Montoya S, Black SA, et al. Editor's choice - European Society for Vascular Surgery (ESVS) 2021 clinical practice guidelines on the Management of Venous Thrombosis. Eur J Vasc Endovasc Surg. 2021;61(1):9-82. https://doi.org/10.1016/j.ejvs.2020.09.023.

9. Zuker-Herman R, Ayalon Dangur I, Berant R, Sitt EC, Baskin L, Shaya Y, et al. Comparison between two-point and three-point compression ultrasound for the diagnosis of deep vein thrombosis. J Thromb Thrombolysis. 2018; 45(1):99-105. https://doi.org/10.1007/s11239-017-1595-9.

10. Adhikari S, Zeger W, Thom C, Fields JM. Isolated deep venous thrombosis: implications for 2-point compression ultrasonography of the lower extremity. Ann Emerg Med. 2015;66(3):262-6. https://doi.org/10.1016/j.a nnemergmed.2014.10.032.

11. Lee JH, Lee SH, Yun SJ. Comparison of 2-point and 3-point point-of-care ultrasound techniques for deep vein thrombosis at the emergency department: A meta-analysis. Medicine (Baltimore). 2019;98:e15791. https:// doi.org/10.1097/MD.0000000000015791.

12. Kruger PC, Eikelboom JW, Douketis JD, Hankey GJ. Deep vein thrombosis: update on diagnosis and management. Med J Aust. 2019;210(11):516-24. https://doi.org/10.5694/mja2.50201.

13. Cabrera R, Chimalakonda N, Rosario J, Ganti L. The role of serial ultrasounds in diagnosing suspected deep venous thrombosis. Cureus. 2019;11:e4337. https://doi.org/10.7759/cureus.4337.

14. Bernardi E, Camporese G, Büller HR, Siragusa S, Imberti D, Berchio A, et al. Serial 2-point ultrasonography plus D-dimer vs whole-leg color-coded Doppler ultrasonography for diagnosing suspected symptomatic deep vein thrombosis: a randomized controlled trial. JAMA. 2008;300(14):1653-9. https://doi.org/10.1001/jama.300.14.1653.

15. Ageno W, Camporese G, Riva N, lotti M, Bucherini E, Righini M, et al. Analysis of an algorithm incorporating limited and whole-leg assessment of the deep venous system in symptomatic outpatients with suspected deep-vein thrombosis (PALLADIO): a prospective, multicentre, cohort study. Lancet Haematol. 2015;2(11):e474-80. https://doi.org/10.1016/S2352-3026(15)00190-8.

16. Cogo A, Lensing AW, Koopman MM, Piovella F, Siragusa S, Wells PS, et al. Compression ultrasonography for diagnostic management of patients with clinically suspected deep vein thrombosis: prospective cohort study. BMJ. 1998;316(7124):17-20. https://doi.org/10.1136/bmj.316.7124.17.

17. Palareti G. How I treat isolated distal deep vein thrombosis (IDDVT). Blood. 2014;123(12):1802-9. https://doi.org/10.1182/blood-2013-10-512616.

18. Gillet J-L, Perrin MR, Allaert FA. Short-term and mid-term outcome of isolated symptomatic muscular calf vein thrombosis. J Vasc Surg. 2007;46(3): 513-9; discussion 519. https://doi.org/10.1016/j.jvs.2007.04.040.

19. Righini M, Galanaud J-P, Guenneguez H, Brisot D, Diard A, Faisse P, et al. Anticoagulant therapy for symptomatic calf deep vein thrombosis (CACTUS): a randomised, double-blind, placebo-controlled trial. Lancet Haematol. 2016; 3(12):e556-62. https://doi.org/10.1016/S2352-3026(16)30131-4.

20. Schwarz T. Therapy of isolated calf muscle vein thrombosis: a randomized, controlled study. J Vasc Surg. 2010;52(5):1246-50. https://doi.org/10.1016/j. jvs.2010.05.094.

21. Masuda EM, Kistner RL, Musikasinthorn C, Liquido F, Geling O, He Q. The controversy of managing calf vein thrombosis. J Vasc Surg. 2012:55(2):55061. https://doi.org/10.1016/j.jvs.2011.05.092.
22. Garcia R, Probeck K, Elitharp DM, Gasparis AP, Labropoulos N. Diverse management of isolated calf deep venous thrombosis in a university hospital. J Vasc Surg Venous Lymphat Disord. 2018;6(2):139-45. https://doi. org/10.1016/j.jvsv.2017.08.021.

23. Robert-Ebadi H, Righini M. Should we diagnose and treat distal deep vein thrombosis? Hematology Am Soc Hematol Educ Program. 2017;2017(1): 231-6. https://doi.org/10.1182/asheducation-2017.1.231.

24. Righini M. Is it worth diagnosing and treating distal deep vein thrombosis? No. J Thromb Haemost. 2007;5(Suppl 1):55-9. https://doi.org/10.1111/j.15387836.2007.02468.x

25. Righini M, Paris S, Le Gal G, Laroche J-P, Perrier A, Bounameaux H. Clinical relevance of distal deep vein thrombosis. Thromb Haemost. 2006;95(01):5664. https://doi.org/10.1160/TH05-08-0588.

26. Sartori M, Cosmi B, Legnani C, Favaretto E, Valdré L, Guazzaloca G, et al. The Wells rule and $\mathrm{D}$-dimer for the diagnosis of isolated distal deep vein thrombosis. J Thromb Haemost. 2012;10(11):2264-9. https://doi.org/10.1111/ j.1538-7836.2012.04895.x.

27. Beller E, Becher M, Meinel FG, Kröger J-C, Rajagopal R, Höft R, et al. Prevalence and predictors of alternative diagnoses on whole-leg ultrasound negative for acute deep venous thrombosis. BMC Med Imaging. 2020;20(1): 127. https://doi.org/10.1186/s12880-020-00527-7.

28. Bressollette L, Nonent M, Oger E, Garcia JF, Larroche P, Guias B, et al. Diagnostic accuracy of compression ultrasonography for the detection of asymptomatic deep venous thrombosis in medical patients--the TADEUS project. Thromb Haemost. 2001;86(08):529-33. https://doi.org/10.1055/s-003 7-1616081.

29. Galanaud J-P, Sevestre-Pietri M-A, Bosson J-L, Laroche J-P, Righini M, Brisot $D$, et al. Comparative study on risk factors and early outcome of symptomatic distal versus proximal deep vein thrombosis: results from the OPTIMEV study. Thromb Haemost. 2009;102(09):493-500. https://doi.org/1 0.1160/TH09-01-0053.

30. Elias A, Mallard L, Elias M, Alquier C, Guidolin F, Gauthier B, et al. A single complete ultrasound investigation of the venous network for the diagnostic management of patients with a clinically suspected first episode of deep venous thrombosis of the lower limbs. Thromb Haemost. 2003;89(2):221-7. https://doi.org/10.1055/s-0037-1613435.

31. Schellong S, Schwarz T, Halbritter K, Beyer J, Siegert G, Oettler W, et al. Complete compression ultrasonography of the leg veins as a single test for the diagnosis of deep vein thrombosis. Thromb Haemost. 2003;89(02):22834. https://doi.org/10.1055/s-0037-1613436.

32. Sevestre M-A, Labarère J, Casez P, Bressollette L, Taiar M, Pernod G, et al. Accuracy of complete compression ultrasound in ruling out suspected deep venous thrombosis in the ambulatory setting. A prospective cohort study. Thromb Haemost. 2009;102(07):166-72. https://doi.org/10.1160/TH09-01-0048.

33. de Maeseneer MGR, Bochanen N, van Rooijen G, Neglén P. Analysis of 1,338 patients with acute lower limb deep venous thrombosis (DVT) supports the inadequacy of the term "proximal DVT". Eur J Vasc Endovasc Surg. 2016; 51(3):415-20. https://doi.org/10.1016/.ejvs.2015.11.001.

34. Roumen-Klappe EM, den Heijer M, van Uum SHM, van der Ven-Jongekrijg J, van der Graaf F, Wollersheim H. Inflammatory response in the acute phase of deep vein thrombosis. J Vasc Surg. 2002;35(4):701-6. https://doi.org/10.1 067/mva.2002.121746.

35. Kearon C, Julian JA, Newman TE, Ginsberg JS. Noninvasive diagnosis of deep venous thrombosis. McMaster diagnostic imaging practice guidelines initiative. Ann Intern Med. 1998;128(8):663-77. https://doi.org/10.7326/ 0003-4819-128-8-199804150-00011.

36. Donadini MP, Dentali F, Pegoraro S, Pomero F, Brignone C, Guasti L, et al. Long-term recurrence of venous thromboembolism after short-term treatment of symptomatic isolated distal deep vein thrombosis: a cohort study. Vasc Med. 2017;22(6):518-24. https://doi.org/10.1177/1358863X17720531.

\section{Publisher's Note}

Springer Nature remains neutral with regard to jurisdictional claims in published maps and institutional affiliations. 